\title{
EGR Strategy for NOx Emission Reduction in a CAI Engine Fuelled with Innovative Biogas
}

\author{
Antonio Mariani, Andrea Unich, Mario Minale* \\ Department of Engineering - Università della Campania “L. Vanvitelli” Via Roma 29, Aversa (CE) 81031, Italy
}

Corresponding Author Email: mario.minale@unicampania.it

https://doi.org/10.18280/ti-ijes.632-444

Received: 18 January 2019

Accepted: 20 April 2019

\section{Keywords:}

EGR strategy, biogas, internal combustion engines (ICE), controlled auto ignition (CAI)

\begin{abstract}
Gaseous fuel utilization reduces pollutant emissions and makes thermal energetic systems less dependent on oil. Their carbon content is low, which means low $\mathrm{CO}_{2}$ emissions, and a lower cost with respect to conventional fuels.

If gaseous fuels have a non-fossil origin, their adoption would have a beneficial impact on global $\mathrm{CO}_{2}$ balance and on the dependence of the energy sector from fossil fuels.

Biogas is produced from the anaerobic digestion of organic materials, with the composition depending on the feedstock and on the production processes.

The use of biogas in internal combustion engines (ICE) is very attractive. However, the presence in the biogas of an inert gas like $\mathrm{CO}_{2}$ has adverse effects on combustion, reducing combustion speed, narrowing flammability limits with harmful effects on combustion stability. A possible way for improving combustion performance of biogas is hydrogen addition. Innovative anaerobic digestion processes, which maximize the $\mathrm{H}_{2}$ yield, can end up with biogases made of $\mathrm{CH}_{4}, \mathrm{CO}_{2}$ and $\mathrm{H}_{2}$.

The biogas, generally adopted as fuel in positive ignition ICEs, is also suitable for Controlled Auto Ignition (CAI) engines.

Aim of this work is to investigate the biogas combustion in CAI ICE by means of numerical simulations. The effect of fuel composition and EGR on engine performance and exhaust emissions was evaluated. Authors compared conventional and innovative biogases composed by $\mathrm{CH}_{4}, \mathrm{CO}_{2}$ and $\mathrm{H}_{2}$ of different compositions. CAI systems are controlled with varying intake gas conditions: air-fuel ratio, boost pressure and charge temperature. The temperature depends on recycled exhaust gas content, which has an impact on the combustion process. Authors investigated the effect that EGR has on the in-cylinder gas temperature and reaction mechanism, focusing on NOx emission formations.
\end{abstract}

\section{INTRODUCTION}

Energy sources depletion and fossil fuels cost are main concerns for nowadays society. Unconventional oils [1] represent the vast majority of the world oil reserves and their exploitation is technically difficult and expensive [2]. Moreover, the increasing energy demand and the effect on climate induced by carbon dioxide and other greenhouse gases force the development of technologies for the use of renewable energy.

Biofuels represent an important option as their production and usage is spreading thanks to the advantages they offer in terms of immediate energy availability and reduced environmental impact. A correct life cycle assessment can demonstrate that the use of biogases as fuels in energy conversion systems can strongly contribute to $\mathrm{CO}_{2}$ emission reduction [3]. As a consequence, European Union is nowadays forcing the use of biofuels. In fact the European directive on renewable energy (Directive 2009/28/EC) [4] establishes that all EU countries must ensure that at least $10 \%$ of their fuels for road vehicles come from renewable sources by 2020 .

Most common biofuels are bioethanol, biodiesel and biogas.

Bioethanol is a liquid biofuel that can be used in spark ignition engines both blended with gasoline at 10 and $20 \%$ (E10, E20, etc.), or as an almost pure fuel (E85, E100), the number representing the ethanol percentage content in the blend [5]. Moreover, if blended with diesel oils, it can also be used in compression ignition engine [6].

Biodiesel derived from the transesterification of vegetable oils [7] can be straightforwardly used in diesel engine. Both biodiesel and bioethanol, generally, can be used with minor engine modifications or no modifications when present in low percentages [3].

Biogas is produced from the anaerobic digestion of organic matter and its constituents are mainly methane and carbon dioxide. The most important raw materials for biogas production are municipal solid waste [8], farm waste, domestic garbage landfills [9], sewage sludge [10], agricultural products, rice paddies waste, energy crops, palm oil mill effluents [11], animal manure [12, 13] and coal mining waste [14].

Despite its composition depends on the feedstock and the production process, conventional biogas is typically composed of 55-65\% of methane, 30-40\% carbon dioxide, and traces of hydrogen sulphide. The aerobic decomposition of the organic matter produces greenhouse gases, so the use of biogas as a fuel is particularly beneficial for the environment.

The use of biogas in internal combustion engines is therefore very attractive even if the presence of an inert gas like $\mathrm{CO}_{2}$ has adverse effects on combustion, reducing combustion speed and narrowing flammability limits $[15,16]$. In internal combustion engines a slower combustion causes a larger combustion angle with a consequent negative effect on 
engine thermal efficiency [17]. The presence of $\mathrm{CO}_{2}$ also reduces the combustion stability [18]. As the flame speed slows down due to the presence of inert gases, combustion evolution becomes erratic and significant differences appear between consecutive indicated cycles. Such cyclic variations cannot exceed an upper threshold, expressed as the Coefficient of Variation (COV) of either the indicated work or the peak cylinder pressure. If such limits are overcome, engine operation becomes unacceptably irregular [19].

Hydrogen addition to the gaseous fuel represents a way to increase the combustion speed. Ma et al. [20] experimentally investigated a lean burn engine fuelled with hydrogenenriched natural gas, observing a reduction of the combustion angle as hydrogen content increased. The addition of hydrogen in gaseous fuels also improves combustion stability, reducing cycle-by-cycle variations. Indeed, Mariani et al. observed a reduction of $\mathrm{COV}$ in indicated mean effective pressure promoted by hydrogen addition to natural gas in a spark ignition engine [21].

The effect of the addition of hydrogen to a biogas was also investigated in the literature, particularly in spark ignition engines [22]. Chung et al. [23] studied the combustion performance of $\mathrm{H}_{2} /$ biogas in a spark ignition engine by numerical simulation; they showed that the rate of heat release increases while increasing $\mathrm{H}_{2}$ content. Rakopoulos et al. [24] used a quasi-dimensional multi-zone model to study the biogas/hydrogen combustion in a single cylinder engine; they concluded that the addition of increasing amounts of $\mathrm{H}_{2}$ in biogas results in a decrease of the flame development period. Park et al. studied the performance and emission characteristics of biogas mixed with hydrogen in SI engine [25, 26]. They found out that the presence of inert gases in the biogas can improve the thermal efficiency and reduce the NOx emissions, though, $\mathrm{HC}$ emissions and cycle variation increase. $\mathrm{Li}$ et al. investigated the effect of hydrogen enrichment on combustion and heat release of a biogas; they concluded that the overall reaction rate increases with $\mathrm{H}_{2}$ concentration [27].

Part load operation is a very frequent condition for internal combustion engines, especially for road vehicle applications. At such operating conditions the engine efficiency is negatively affected by the combined effect of the increased relative incidence of rubbing friction and, in spark ignition engines, by intake air throttling losses [19]. An alternative to the conventional spark ignited combustion is the Controlled Auto-Ignition (CAI) combustion, allowing operating the engine at part loads with considerable excess of air, so eliminating the need for throttling. CAI combustion is governed by auto ignition instead of by spark ignition and subsequent flame front propagation [28]. Thanks to its characteristics, CAI engines attracted some attention in the literature [29-32]. The combustion is characterized by the absence of a flame front propagation and by an extremely rapid evolution. This allows an efficiency improvement, limited however by the constraint that cylinder pressure rise rate cannot exceed some limits in order to prevent unacceptable mechanical and thermal loads [29]. Biogases were also used to fuel CAI engines and the influence of the amount of recycled combustion products on combustion timing and angular duration was investigated [30]; Jamsaran et al. [33] investigated the auto-ignition reactivity of natural gas with regard to the effects of intake air temperature and equivalence ratio; Nishi et al. [34] studied the effects of EGR ratio and engine speed on HCCI combustion; Ibrahim et al. [35] improved the performance and extended the load range of hydrogen fuelled homogeneous charge compression ignition (HCCI) engine through charge temperature control and $\mathrm{CO}_{2}$ dilution.

Another important aspect related to the use of biogas as fuel in spark ignition internal combustion engines is the reduction of power due to the presence of the inert gases. In biogas fuelled CAI engines it is possible to compensate for the presence of $\mathrm{CO}_{2}$ in the fuel by changing (increasing) the equivalence ratio. In fact CAI's are operated at lean conditions giving the possibility to control load by varying the ER. In this way the engine would not be affected by any power reduction.

It was already proven that fuelling a CAI engine with hydrogen enriched methane contributes to reduce NOx emissions, essentially because the intake gas temperature, controlled with EGR, is lower than what is required for the auto-ignition of pure methane [36]. Furthermore, a preliminary simplified analysis, where the intake gas temperature is considered as a parameter of the problem, confirmed the NOx emissions reduction also when a CAI engine is fuelled with biogases made of methane, carbon dioxide and hydrogen [37]. Aim of this paper is the investigation of the effects on CAI engine performance and NOx emissions of the use of innovative biogases made of $\mathrm{CH}_{4}, \mathrm{H}_{2}$ and $\mathrm{CO}_{2}$, adopting EGR for controlling auto-ignition and combustion phasing. The engine load is here managed by changing the intake charge pressure at constant equivalence ratio. Results show that the innovative biogases allow a very promising reduction of NOx emissions with respect to that of a conventional biogas, mainly due to less boosting and EGR rate requirements, for delivering a reference imep.

\section{METHODS}

\subsection{CAI engine}

Controlled Auto-Ignition combustion combines the advantages of spark ignition and compression ignition engines. The combustion is characterized by an extremely rapid evolution with high thermal efficiency. However, the cylinder pressure rise rate tends to be very sharp and, if not limited, it can lead to unacceptable mechanical and thermal loads and noise. With the absence of flame front propagation, CAI combustion is dominated by chemical kinetics. Implementation of a detailed reaction mechanism is therefore necessary for CAI combustion analysis. The complex gasphase chemical kinetics is here modelled with the detailed radical chain reaction mechanism GRI-Mech 3.0 [38], designed for methane. It is made of 325 elementary chemical reactions and 53 species, including those to predict NOx formation; all kinetic constants are provided. GRI-Mech 3.0 mechanism includes all the reactions required to accurately describe both biogas and hydrogen combustion, also allowing to consider the effect of EGR on the auto-ignition, reaction rates and emission formation.

The combustion process of a CAI engine is studied using the Package HCCI of Chemkin 17.0 [39]. The engine cycle simulation does not consider the gas exchange process. The CAI model predicts the combustion in an internal combustion engine under auto-ignition conditions. The implemented single-zone CAI combustion model permits detailed description of the chemical kinetics by assuming homogeneous gas properties in the combustion chamber. The single-zone model can adequately predict the ignition. 
However, because it does not account for low-temperature regions within the thermal boundary layers and crevices, the model underestimates carbon monoxide and unburned hydrocarbon emissions. For this reason here the authors focused on NOx emissions only. The main characteristics of the engine selected for the simulations are reported in Table 1. This type of engine is used for stationary applications, i.e. power generation at constant engine speed (usually $1500 \mathrm{rpm}$ ). The investigated engine is supercharged; as a consequence cylinder pressure at start of compression is above ambient pressure. Temperature at start of compression can be controlled by varying the amount of residual gases in the cylinder using an EGR system [30-32]. The presence of residual gases has an impact on the combustion process as the burning mixture composition consequently changes.

Table 1. Engine parameters and operating conditions

\begin{tabular}{cc}
\hline Engine type & 4-stroke \\
\hline Compression ratio & $16.7: 1$ \\
Bore $[\mathrm{mm}]$ & 135 \\
Stroke $[\mathrm{mm}]$ & 170 \\
Engine speed $[\mathrm{rpm}]$ & 1500 \\
\hline
\end{tabular}

\subsection{Biogas}

Biogas is typically obtained from the dark anaerobic digestion of organic matter and mainly composed of methane and carbon dioxide. The molar ratio $\mathrm{CH}_{4} / \mathrm{CO}_{2}$ in a biogas can be predicted with the Buswell equation for the anaerobic digestion of organic matter [40]:

$$
\begin{gathered}
\mathrm{C}_{\mathrm{n}} \mathrm{H}_{\mathrm{a}} \mathrm{O}_{\mathrm{b}} \mathrm{N}_{\mathrm{d}}+\left(\mathrm{n}-\frac{\mathrm{a}}{4}-\frac{\mathrm{b}}{2}+\frac{3 \mathrm{~d}}{4}\right) \mathrm{H}_{2} \mathrm{O} \rightarrow\left(\frac{\mathrm{n}}{2}+\frac{\mathrm{a}}{8}-\frac{\mathrm{b}}{4}-\right. \\
\left.\frac{3 \mathrm{~d}}{8}\right) \mathrm{CH}_{4}+\left(\frac{\mathrm{n}}{2}-\frac{\mathrm{a}}{8}+\frac{\mathrm{b}}{4}+\frac{3 \mathrm{~d}}{8}\right) \mathrm{CO}_{2}+\mathrm{dNH}_{3}
\end{gathered}
$$

Equation (1) predicts a $\mathrm{CH}_{4} / \mathrm{CO}_{2}$ ratio ranging from 1 , for simple carbohydrates like starch $\left(\mathrm{C}_{6} \mathrm{H}_{10} \mathrm{O}_{5}\right) \mathrm{n}$, or proteins $\left(\mathrm{C}_{5} \mathrm{H}_{7} \mathrm{NO}_{2}\right)$ to 2.35 , for the conversion of lipids, e.g., $\mathrm{C}_{57} \mathrm{H}_{104} \mathrm{O}_{6}$. It is experimentally found that for the anaerobic digestion of water buffalo manure the $\mathrm{CH}_{4} / \mathrm{CO}_{2}$ ratio is about 2 [41, 42]. Being 2 an intermediate value, it was decided to keep the $\mathrm{CH}_{4} / \mathrm{CO}_{2}$ ratio constant and equal to 2 for all biogases considered in the present study.

Hydrogen is an intermediate product of the anaerobic fermentation and thus, if the digestion process is accurately designed and controlled the $\mathrm{H}_{2}$ yield can be maximized so to produce an innovative biogas mainly made of $\mathrm{CH}_{4}, \mathrm{H}_{2}$ and $\mathrm{CO}_{2}$ [44]. Water buffalo manure naturally contains the eubacteria responsible of the hydrogen production [43] and thus it can be considered as a very promising substrate to produce the innovative biogas [45]. The authors then assumed water buffalo manure as a reference organic matter from which, as experimentally demonstrated, an innovative biogas with an $\mathrm{H}_{2} / \mathrm{CO}_{2}$ molar ratio of about 1 and a maximum $\mathrm{H}_{2} / \mathrm{CH}_{4}$ molar ratio of 0.25 can be produced [46]. The authors thus decided to keep $\mathrm{H}_{2} / \mathrm{CO}_{2}$ molar ratio value constant and equal to 1 in the innovative biogases studied and to investigate two different $\mathrm{H}_{2} / \mathrm{CH}_{4}$ ratios equal to $1 / 9$ and $2 / 8$, respectively. As a matter of comparison also a traditional biogas without $\mathrm{H}_{2}$ is investigated.

Fuel compositions are summarized in Table 2.
Table 2. Fuels composition

\begin{tabular}{cccc}
\hline Fuel & $\begin{array}{c}\mathrm{CH}_{4} \\
\text { mol. fraction }\end{array}$ & $\begin{array}{c}\mathbf{H}_{2} \\
\text { mol. fraction }\end{array}$ & $\begin{array}{c}\mathbf{C O}_{2} \\
\text { mol. fraction }\end{array}$ \\
\hline Biogas 1 & 0.67 & 0 & 0.33 \\
Biogas 2 & 0.580 & 0.065 & 0.355 \\
Biogas 3 & 0.500 & 0.125 & 0.375 \\
\hline
\end{tabular}

\subsection{Hydrogen}

Hydrogen is a gas of very low density with a critical temperature of $-239.91^{\circ} \mathrm{C}$. On volume basis, it requires less air than methane for a stoichiometric combustion whereas it is the opposite on mass basis. The effect of the low hydrogen density is important also on the heating value. When the mass based lower heating value is considered, hydrogen shows a very high energy content per $\mathrm{kg}$ of gas, much higher than methane, conversely on volumetric base the opposite holds. Hydrogen has a higher auto-ignition temperature, thermal conductivity and Octane Number than methane. In spark ignition engines, important properties are also its fast flame speed and wide flammability limits. It is important to consider hydrogen properties in the model in order to understand the effect on the combustion process.

\subsection{Engine operating parameters}

The equivalence ratio (ER) is defined as the ratio between the actual and the stoichiometric fuel-to-air mass ratio:

$E R=\frac{\left(\frac{m_{f}}{m_{a}}\right)_{\text {actual }}}{\left(\frac{m_{f}}{m_{a}}\right)_{\text {stoic. }}}$

CAI's operate with lean air-fuel mixtures $(\mathrm{ER}<1)$ in order to have a better control of pressure gradient in the cylinder. For this reason the analysis is carried out considering a reference ER of 0.4 [30].

Indicated Mean Effective Pressure (imep) is an engine performance index independent from engine size, obtained dividing the indicated work per cycle by the displacement, $V_{d}$ :

imep $=\frac{\oint p d V}{V_{d}}$

Engine indicated efficiency is defined as:

$\eta_{i}=\frac{P_{i}}{\dot{m}_{f} \cdot L H V}$

where $\mathrm{P}_{\mathrm{i}}$ is the indicated power, $\dot{m}_{f}$ is the fuel mass flow, LHV the lower heating value of the fuel.

\section{RESULTS AND DISCUSSION}

\subsection{Biogas: Effect of EGR}

The intake temperature is an important control parameter for the combustion in CAI's. The combustion takes place only if the in-cylinder gases reach the conditions for the autoignition. Engine performance strongly depends on the initial gas temperature as it directly affects the combustion phasing relative to the top dead center. In CAI's the temperature can be controlled with varying the EGR rate. Hot exhaust gases are 
recirculated and mixed with the fresh charge, an air-fuel mixture whose composition is defined by the ER. The air is usually mixed with the fuel downstream the compressor. Normally, in boosted i.c. engines, the air is cooled down before entering the cylinders to improve volumetric efficiency and reduce knock. In this analysis the air cooler was not considered because the air temperature increase due to the compression is beneficial for auto-ignition. Intake temperature consequently depends on the compressor pressure ratio and EGR rate.

Figure 1 shows the effect of EGR on Biogas 1 combustion at intake pressure equal to $230.5 \mathrm{kPa}$ and intake temperature, equal to $435 \mathrm{~K}$. The temperature and pressure traces are plotted versus the crank angle in Figure 1a and 1b, respectively. With no EGR the combustion does not take place and for this reason the corresponding temperature and pressure traces were not included in the plots. As the EGR rate increases from $10 \%$ to $20 \%$, the combustion start angle moves towards top dead center because in-cylinder gases reach earlier the thermodynamic conditions for the auto-ignition. Engine indicated efficiency is consequently affected. In fact, if the auto-ignition occurs too late, the peak cylinder pressure is positioned later in the expansion stroke and is reduced in magnitude with negative effects on imep; if it is too advanced, peak cylinder pressure occurs too early so increasing the compression work [19]. The solid line (10\% EGR) shows the best combustion phasing.
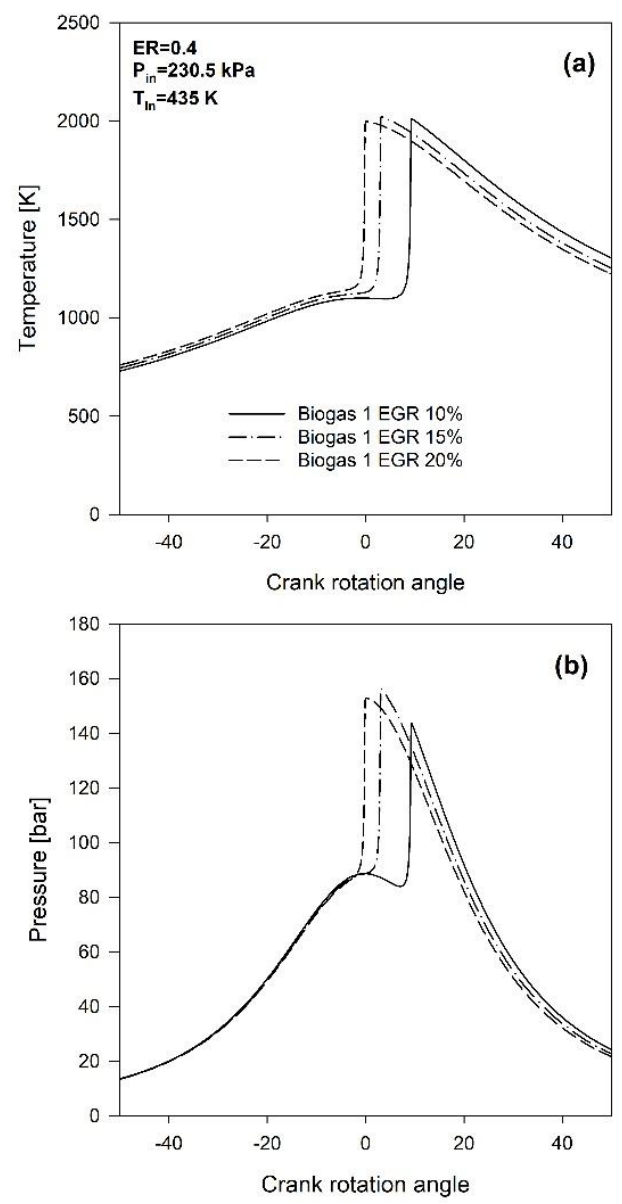

Figure 1. Temperature (a) and Pressure (b) traces vs. crank angle at different EGR rates (Biogas 1)
Figure 2 shows the effect of EGR on engine performance and emissions when Biogas 1 is adopted. Imep (a) and efficiency (b) are higher with $10 \%$ EGR because of better combustion phasing. Conversely, the peak Temperature (c) is essentially unaffected by the EGR. Concerning the NOx emissions (d) the minimum is found with EGR $=10 \%$. Indeed, higher EGR rates reduce the engine power output and cause higher NOx emissions due to higher peak cylinder temperature and/or due to longer exposition of the combustion products to high in-cylinder temperature (see Figure 1a).
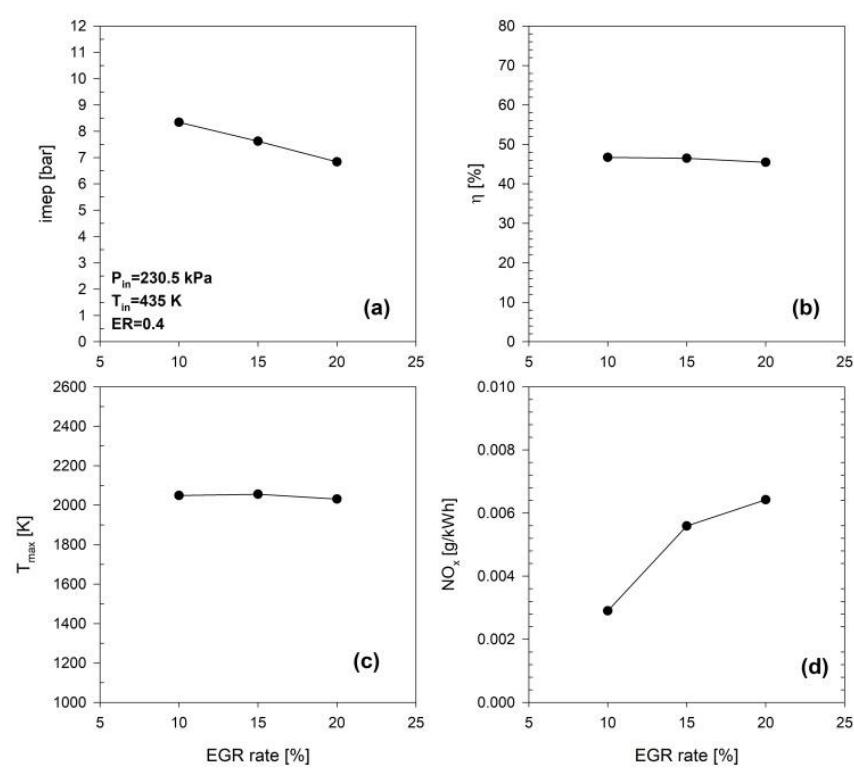

Figure 2. Effect of EGR rate on imep (a), efficiency (b), maximum temperature (c) and NOx emissions (d). Biogas 1

\subsection{Comparison between conventional and innovative biogases}

Innovative biogases (Biogas 2 and 3) contain hydrogen which reduces the auto-ignition temperature requirement in comparison with the conventional biogas (Biogas 1) consequently requiring less EGR rate. Boost pressure should also be adjusted in order to keep the imep constant.

Figure 3 shows the in-cylinder temperature (a) and pressure (b) traces versus the crank angle for Biogas 1, Biogas 2 and Biogas 3. The boost pressure, the intake temperature and the required EGR rates are also indicated for all fuels. The operating conditions were optimized for obtaining 8.4 bar imep with an optimal combustion phasing, keeping the ER at 0.4 . The innovative biogases require less EGR rate $(7 \%)$ than Biogas $1(9 \%)$ for an optimized combustion phasing. The boost pressure also reduces with the presence of hydrogen in the fuel, $230.5 \mathrm{kPa}$ for Biogas 1, $217.8 \mathrm{kPa}$ for Biogas 2 and $216 \mathrm{kPa}$ for Biogas 3. The in-cylinder gas temperature at the beginning of the compression stroke for the innovative biogases is also lower as it is related to the boost pressure.

Cycle averaged results are compared in Figure 4. The engine delivers the target imep (Figure 4a) with a lower peak pressure and a slightly reduced peak temperature (Figure 4c) for the biogases containing hydrogen. Engine efficiency does not change significantly (Figure 4b) while NOx emissions are drastically reduced, from $2.26 \mathrm{mg} / \mathrm{kWh}$ for Biogas 1 to 1.53 $\mathrm{mg} / \mathrm{kWh}$ for Biogas 2 and $1.17 \mathrm{mg} / \mathrm{kWh}$ for Biogas 3, Figure 4 (d). 

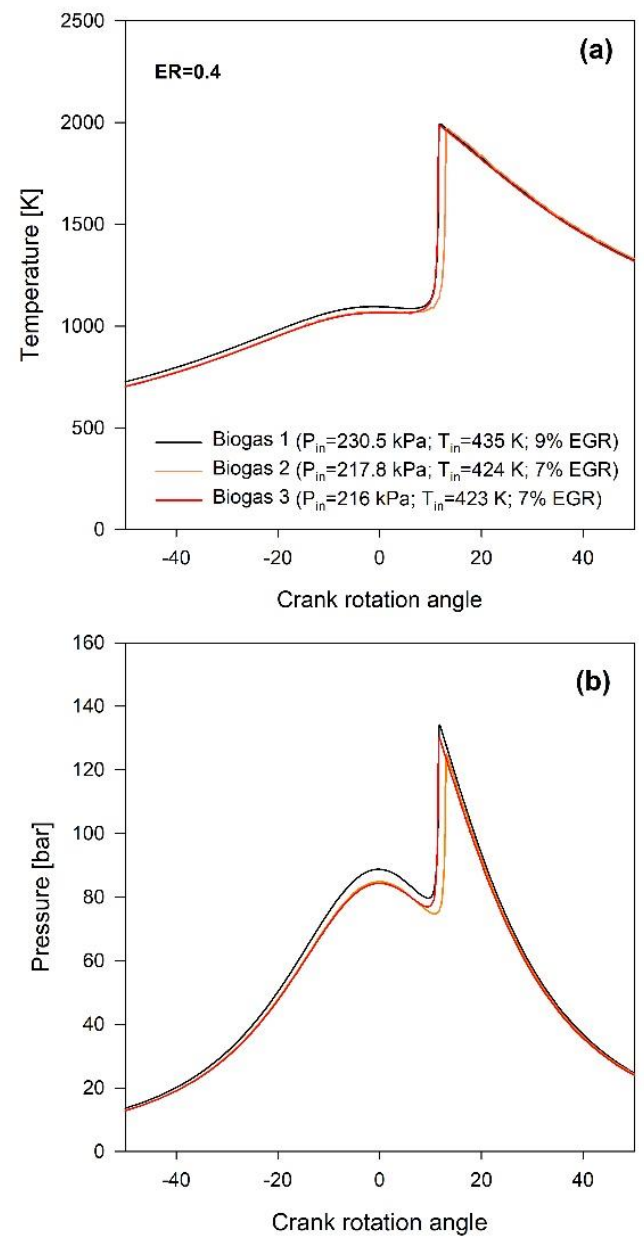

Figure 3. Temperature (a) and Pressure (b) traces versus crank angle for Biogas, Biogas 2 and Biogas 3. Boost pressure and EGR rate optimized for each fuel in order to obtain 8.4 bar imep with maximum engine efficiency
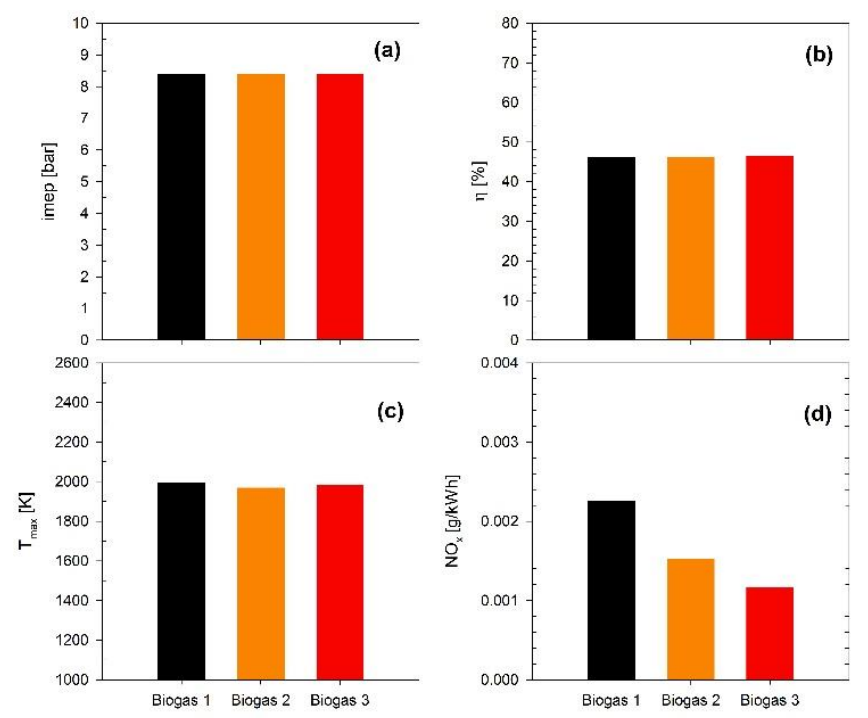

Figure 4. Effect of hydrogen on imep (a), efficiency (b), maximum temperature (c) and NOx emissions (d)

\section{CONCLUSIONS}

The paper describes a numerical study on a Controlled Auto
Ignition engine fed by a conventional biogas (Biogas 1) and innovative biogases containing hydrogen (Biogas 2 and Biogas 3). The model predicts indicated mean effective pressure, indicated efficiency and NOx emissions.

The engine was operated in order to obtain a reference imep value of 8.4 bar with an ER=0.4. The EGR rate was adjusted for each fuel in order to obtain an optimal combustion phasing.

The results show that hydrogen addition reduces the intake temperature requirement for the auto-ignition. As a consequence the innovative biogases require less EGR rate (7 \% EGR for both Biogas 2 and 3) than Biogas 1 (9 \% EGR required).

The boost pressure also reduces with hydrogen, from 230.5 $\mathrm{kPa}$ for Biogas 1, to $217.8 \mathrm{kPa}$ for Biogas 2 and $216 \mathrm{kPa}$ for Biogas 3.

Engine efficiency does not change significantly between tested fuels for the operating conditions considered. The fact that the presence of hydrogen does not bring an appreciable benefit in terms of engine efficiency can be explained taking into consideration the combustion characteristic of a CAI engine: it burns so fast (also without hydrogen) that any increase in the reaction rates due to the presence of hydrogen is not appreciable in terms of engine thermal efficiency.

The most important result is the potential benefit of innovative biogases in terms of NOx emission reduction. In fact, due to the lower boost pressure and EGR requirements Biogas 2 and Biogas 3 emit less NOx, respectively 1.53 $\mathrm{mg} / \mathrm{kWh}$ and $1.17 \mathrm{mg} / \mathrm{kWh}$, than Biogas 1, $2.26 \mathrm{mg} / \mathrm{kWh}$ for Biogas 1.

\section{REFERENCES}

[1] Merola MC, Carotenuto C, Gargiulo V, Stanzione F, Ciajolo A, Minale M. (2016). Chemical-physical analysis of rheologically different samples of a heavy crude oil. Fuel Processing Technology 148: 236-247. http://dx.doi.org/10.1016/j.fuproc.2016.03.001

[2] Minale M, Merola MC, Carotenuto C. (2018). Effect of solvents on the microstructure aggregation of a heavy crude oil. Fuel Processing Technology 177: 299-308. https://doi.org/10.1016/j.fuproc.2018.05.016

[3] Ahindra N. (2008). Biofuels refinancing and performance. New York: McGraw-Hill.

[4] European Parliament. (2009). Directive 2009/28/EC of the European Parliament and of the Council of 23 April 2009 on the Promotion of the use of Energy from Renewable Sources and Amending and Susequently Repealing Directives 2001/77/EC and 2003/30/EC. http://data.europa.eu/eli/dir/2009/28/oj

[5] Thangavelu SK, Ahmed AS, Ani FN. (2016). Review on bioethanol as alternative fuel for spark ignition engines. Renewable and Sustainable Energy Reviews 56: 820-835. https://doi.org/10.1016/j.rser.2015.11.089

[6] Mata C, Gómez A, Armas O. (2017). The influence of ethanol-diesel blend on pollutant emissions from different bus fleets under acceleration transitions. Fuel 209: 322-328. https://doi.org/10.1016/j.fuel.2017.08.018

[7] Liu S, Chen W, Zhu Z, Jiang S, Ren T, Guo H. (2018). A review of the developed new model biodiesels and their effects on engine combustion and emissions. Applied Sciences 8(11): 2303.

[8] Souza-Santos MLD, Ceribeli K. (2013). Technical evaluation of a power generation process consuming 
municipal solid waste. Fuel 108: 578-585. https://doi.org/10.1016/j.fuel.2012.12.037

[9] Rasi S, Läntelä J, Rintala J. (2014). Upgrading landfill gas using a high pressure water absorption process. Fuel 115: 539-543. https://doi.org/10.1016/j.fuel.2013.07.082

[10] Yuan W, Bandosz TJ. (2007). Removal of hydrogen sulfide from biogas on sludge-derived adsorbents. Fuel 86(17):

2736-2746 https://doi.org/10.1016/j.fuel.2007.03.012

[11] Chin MJ, Poh PE, Tey BT, Chan ES, Chin KL. (2013). Biogas from palm oil mill effluent (POME): Opportunities and challenges from Malaysia's perspective. Renewable and Sustainable Energy Reviews 26: 717-726. https://doi.org/10.1016/j.rser.2013.06.008

[12] Guarino G, Carotenuto C, Cristofaro FD, Papa S, Morrone B, Minale M. (2016). Does the C/N ratio really affect the bio-methane yield? A three years investigation of buffalo manure digestion. Chemical Engineering Transactions 49: 463-468. https://doi.org/10.3303/CET1649078

[13] Thu CTT, Cuong PH, Hang LT, Chao NV, Anh LX, Trach NX, Sommer SG. (2012). Manure management practices on biogas and non-biogas pig farms in developing countries - using livestock farms in Vietnam as an example. Journal of Cleaner Production 27: 64-71. https://doi.org/10.1016/j.jclepro.2012.01.006

[14] Luo D, Dai Y. (2009). Economic evaluation of coalbed methane production in China. Energy Policy 37(10): 3883-3889. https://doi.org/10.1016/j.enpol.2009.06.049

[15] Hinton N, Stone R. (2014). Laminar burning velocity measurements of methane and carbon dioxide mixtures (biogas) over wide ranging temperatures and pressures. Fuel 116:

$743-750$ https://doi.org/10.1016/j.fuel.2013.08.069

[16] Yadav VK, Ray A, Ravi MR. (2019). Experimental and computational investigation of the laminar burning velocity of hydrogen-enriched biogas. Fuel 235: 810-821. https://doi.org/10.1016/j.fuel.2018.08.068

[17] Ferguson CR, Kirkpatrick AT. (2000). Internal combustion engines: Applied thermo sciences. Second ed. New York: Wiley \& Sons.

[18] Hu Z, Zhang X. (2013). Experimental study on flame stability of biogas / hydrogen combustion. International Journal of Hydrogen Energy 44(11): 5607-5614. https://doi.org/10.1016/j.ijhydene.2018.08.011

[19] Heywood JB. (1988). Internal Combustion Engine Fundamentals. New York, NY, USA: McGraw-Hill.

[20] Ma F, Wang Y, Liu H, Li Y, Wang J, Ding S. (2008). Effects of hydrogen addition on cycle-by-cycle variations in a lean burn natural gas spark-ignition engine. International Journal of Hydrogen Energy 33(2): 823831. https://doi.org/10.1016/j.ijhydene.2007.10.043

[21] Mariani A, Prati MV, Unich A, Morrone B. (2013). Combustion analysis of a spark ignition i. c. engine fuelled alternatively with natural gas and hydrogennatural gas blends. International Journal of Hydrogen Energy 38(3): https://doi.org/10.1016/j.ijhydene.2012.11.051

[22] Montoya JPG, Amell AA, Olsen DB, Diaz GJA. (2018). Strategies to improve the performance of a spark ignition engine using fuel blends of biogas with natural gas, propane and hydrogen. International Journal of Hydrogen Energy 43(46): 21592-21602. https://doi.org/10.1016/j.ijhydene.2018.10.009
[23] Chung K, Chun KM. (2013). SAE International.

[24] Rakopoulos CD, Michos CN, Giakoumis EG. (2009). Thermodynamic analysis of SI engine operation on variable composition biogas-hydrogen blends using a quasi-dimensional, multi-zone combustion model. SAE International Journal Engines 2(1): 880-910. https://doi.org/10.4271/2009-01-0931

[25] Park C, Park S, Kim C, Lee S. (2012). Effects of EGR on performance of engines with spark gap projection and fueled by biogas-hydrogen blends. International Journal of Hydrogen Energy 37(19): 14640-14648. /https://doi.org/10.1016/j.ijhydene.2012.07.080

[26] Park C, Park S, Lee Y, Kim C, Lee S, Moriyoshi Y. (2011). Performance and emission characteristics of a SI engine fueled by low calorific biogas blended with hydrogen. International Journal of Hydrogen Energy 36(16): 10080-10088. https://doi.org/10.1016/j.ijhydene.2011.05.018

[27] Li J, Huang H, Huhetaoli, Osaka Y, Bai Y, Kobayashi N, Chen Y. (2017). Combustion and heat release characteristics of biogas under hydrogen- and oxygenenriched condition. Energies 10(8): 2017. https://doi.org/10.3390/en10081200

[28] Zhang Y, Zhao H. (2014). Investigation of combustion, performance and emission characteristics of 2-stroke and 4-stroke spark ignition and CAI/HCCI operations in a DI gasoline. Applied Energy 130: 244-255. https://doi.org/10.1016/j.apenergy.2014.05.036

[29] Cho G, Jeong D, Moon G, Bae C. (2010). Controlled auto-ignition characteristics of methane-air mixture in a rapid intake compression and expansion machine. Energy 35(10): 4184-4191. https://doi.org/10.1016/j.energy.2010.07.002

[30] Kozarac D, Vuilleumier D, Saxena S, Dibble RW. (2014). Analysis of benefits of using internal exhaust gas recirculation in biogas-fueled HCCI engines. Energy Conversion and Management 87: 1186-1194. https://doi.org/10.1016/j.enconman.2014.04.085

[31] Saxena S, Bedoya ID. (2013). Fundamental phenomena affecting low temperature combustion and HCCI engines, high load limits and strategies for extending these limits. Progress in Energy and Combustion Science 39(5): 457488. https://doi.org/10.1016/j.pecs.2013.05.002

[32] Yao M, Zheng Z, Liu H. (2009). Progress and recent trends in homogeneous charge compression ignition (HCCI) engines. Progress in Energy and Combustion Science 35(5): 398-437. https://doi.org/10.1016/j.pecs.2009.05.001

[33] Jamsran N, Putrasari Y, Lim O. (2016). A computational study on the autoignition characteristics of an HCCI engine fueled with natural gas. Journal of Natural Gas Science and Engineering 29: 469-478. https://doi.org/10.1016/j.jngse.2016.01.008

[34] Nishi M, Kanehara M, Iida N. (2016). Assessment for innovative combustion on HCCI engine by controlling EGR ratio and engine speed. Applied Thermal Engineering 99: 42-60. https://doi.org/10.1016/j.applthermaleng.2015.11.126

[35] Ibrahim MM, Ramesh A. (2014). Investigations on the effects of intake temperature and charge dilution in a hydrogen fueled HCCI engine. International Journal of Hydrogen Energy 39(26): 14097-14108. https://doi.org/10.1016/j.ijhydene.2014.07.019

[36] Mariani A, Unich A, Minale M. (2019). 
Methane/Hydrogen blends in controlled auto ignition engines with EGR: Evaluation of NOx emissions. Chemical Engineering Transactions 76.

[37] Mariani A, Unich A, Minale M. (2018). Combustion of hydrogen enriched methane and biogases containing hydrogen in a controlled auto-ignition engine. Applied Sciences $8(12)$ : https://doi.org/10.3390/app8122667

[38] GRI-MECH, (Gas Research Institute).

[39] Chemkin. Reaction Design, (San Diego, 2007).

[40] Buswell AM, Mueller HF. (1952). Mechanism of methane fermentation. Industrial \& Engineering Chemistry 44(3): 550-552. https://doi.org/10.1021/ie50507a033

[41] Carotenuto C, Guarino G, Minale M, Morrone B. (2016). Biogas production from anaerobic digestion of manure at different operative conditions. International Journal of Heat and Technology 34(4): 623-629. https://doi.org/10.18280/ijht.340411

[42] Carotenuto C, Guarino G, Morrone B, Minale M. (2016). Temperature and $\mathrm{pH}$ effect on methane production from buffalo manure anaerobic digestion. International Journal of Heat and Technology 34(2): S425-S429. https://doi.org/10.18280/ijht.34S233

[43] Carillo P, Carotenuto C, Cristofaro FD, Kafantaris I, Lubritto C, Minale M, Morrone B, Papa S, Woodrow P. (2012). DGGE analysis of buffalo manure eubacteria for hydrogen production: Effect of $\mathrm{pH}$, temperature and pretreatments. Molecular biology reports 39(12): 1019310200. https://doi.org/10.1007/s11033-012-1894-3

[44] Gilroyed BH, Chang C, Chu A, Hao X. (2008). Effect of temperature on anaerobic fermentative hydrogen gas production from feedlot cattle manure using mixed microflora. International Journal of Hydrogen Energy 33(16):

https://doi.org/10.1016/j.ijhydene.2008.06.016

[45] Guarino G, Cristofaro FD, Carotenuto C, Morrone B, Minale M. (2014). Effect of thermal and mechanical pretreatments on the $\mathrm{CH}_{4}-\mathrm{H}_{2}$ production from water buffalo manure in different process conditions. Chemical Engineering Transactions 38: 205-210. https://doi.org/10.3303/CET1438035

[46] Cristofaro FD, Carotenuto C, Carillo P, Woodrow P, Morrone B, Minale M. (2014). Evaluation of $\mathrm{CH}_{4}$ and $\mathrm{H}_{2}$ yield with different mixtures of digested and fresh buffalo manure. Chemical Engineering Transactions 37: 283-288. https://doi.org/10.3303/CET1437048

\section{NOMENCLATURE}

imep

ER

LHV

NOx

$\mathrm{p}$

$\mathrm{T}$

V

\section{Greek symbols}

$\eta$

\section{Subscripts}

a

d

$\mathrm{f}$

Stoich.
Indicated mean effective pressure, $\mathrm{kPa}$ Equivalence ratio Lower heating value, $\mathrm{MJ} / \mathrm{kg}$ Nitrogen oxides emissions, $\mathrm{g} / \mathrm{kWh}$ Pressure, $\mathrm{kPa}$ Temperature, $\mathrm{K}$ Volume, 1

Engine efficiency

air Displaced volume fuel stoichiometric 